\title{
Large differences in reanalyses of diabatic heating in the tropical upper troposphere and lower stratosphere
}

\author{
J. S. Wright ${ }^{1}$ and S. Fueglistaler ${ }^{2}$ \\ ${ }^{1}$ Ministry of Education Key Laboratory for Earth System Modeling, Center for Earth System Science, \\ Tsinghua University, Beijing, China \\ ${ }^{2}$ Program in Atmospheric and Oceanic Sciences, Department of Geosciences, Princeton University, \\ Princeton, New Jersey, USA
}

Correspondence to: J. S. Wright (jswright@ tsinghua.edu.cn)

Received: 15 March 2013 - Published in Atmos. Chem. Phys. Discuss.: 3 April 2013

Revised: 8 August 2013 - Accepted: 21 August 2013 - Published: 27 September 2013

\begin{abstract}
We present the time mean heat budgets of the tropical upper troposphere (UT) and lower stratosphere (LS) as simulated by five reanalysis models: the Modern-Era Retrospective Analysis for Research and Applications (MERRA), European Reanalysis (ERA-Interim), Climate Forecast System Reanalysis (CFSR), Japanese 25-yr Reanalysis and Japan Meteorological Agency Climate Data Assimilation System (JRA-25/JCDAS), and National Centers for Environmental Prediction/National Center for Atmospheric Research (NCEP/NCAR) Reanalysis 1 . The simulated diabatic heat budget in the tropical UTLS differs significantly from model to model, with substantial implications for representations of transport and mixing. Large differences are apparent both in the net heat budget and in all comparable individual components, including latent heating, heating due to radiative transfer, and heating due to parameterised vertical mixing. We describe and discuss the most pronounced differences. Discrepancies in latent heating reflect continuing difficulties in representing moist convection in models. Although these discrepancies may be expected, their magnitude is still disturbing. We pay particular attention to discrepancies in radiative heating (which may be surprising given the strength of observational constraints on temperature and tropospheric water vapour) and discrepancies in heating due to turbulent mixing (which have received comparatively little attention). The largest differences in radiative heating in the tropical UTLS are attributable to differences in cloud radiative heating, but important systematic differences are present even in the absence of clouds. Local maxima in heating and
\end{abstract}

cooling due to parameterised turbulent mixing occur in the vicinity of the tropical tropopause.

\section{Introduction}

Meteorological analyses and reanalyses are best guesses of the true state of the atmosphere. As such, they are of eminent importance not only for initialisation of weather forecast model runs, but for process analyses and detection and attribution of changes in the climate system. The (re)analysis model state is optimised to observable quantities such as winds, temperature, trace gas mixing ratios (particularly water vapour), and clouds; accordingly, the "analysis step" may not strictly conserve the energy budget of the model state. For example, the moisture assimilation step may add or remove water substance (and hence latent heat), while the temperature assimilation step may add or remove sensible heat. Despite this caveat, (re)analyses are still superior to freerunning general circulation models for a wide range of applications because the latter only allow comparison with observations in a statistical sense.

Here, we present an overview of the diabatic heat budgets of the tropical upper troposphere and lower stratosphere (UTLS) in five widely used reanalyses: the ModernEra Retrospective Analysis for Research and Applications (MERRA; Rienecker et al., 2011), the European Reanalysis (ERA-Interim; Dee et al., 2011), the Climate Forecast System Reanalysis (CFSR; Saha et al., 2010), the Japanese 25-yr Reanalysis (JRA-25) and its continuation with the Japan Meteorological Agency (JMA) Climate Data 
Assimilation System (Onogi et al., 2007), and the National Centers for Environmental Prediction/National Center for Atmospheric Research (NCEP/NCAR) Reanalysis 1 (Kalnay et al., 1996). Fueglistaler et al. (2009b) have previously provided a comparison of the ERA-Interim diabatic heat budget with that of the older ERA-40, and Ling and Zhang (2013) have examined the diabatic heat budgets of MERRA, CFSR, and ERA-Interim at lower levels in the troposphere.

We focus on the tropical UTLS between $300 \mathrm{hPa}$ and $50 \mathrm{hPa}$. This region encompasses the important transition in regime from a balance between latent heating and radiative cooling in the troposphere to a balance between tropical radiative heating and extratropical radiative cooling in the stratosphere. Furthermore, transport into the stratospheric overworld (terminology follows Hoskins, 1991) occurs predominantly in the tropics, and conditions in the tropical tropopause layer (TTL, $\sim 150-70 \mathrm{hPa}$ ) control the stratospheric abundance of a range of radiatively and chemically important trace gases (see review by Fueglistaler et al., 2009a). Uncertainties in model diabatic heat budgets in this layer therefore also affect confidence in model predictions of future stratospheric composition and its radiative impact on climate.

The diabatic heat budget of the TTL (and consequently transport pathways and mechanisms within the TTL) remains a subject of debate (see discussion by Fueglistaler et al., 2009a). In particular, the radiative effects of clouds and the impact of convection that overshoots its level of neutral buoyancy are not well quantified. Both of these processes pose challenges to global-scale numerical models due to the small scales involved. Additional processes, such as mixing related to shear-flow instability, have received comparatively less attention, but should also be discussed as they are highly parameterised and often serve as a "tuning parameter" that compensates for errors in other aspects of the model (see also discussion by Flannaghan and Fueglistaler, 2011).

One may expect the radiative components of reanalyses to be comparatively more accurate because temperature and tropospheric water vapour are well constrained by observations. However, ozone concentrations are also radiatively important in this region and are often not constrained by observations (in several cases, a prescribed climatology is used). Furthermore, cloud radiative effects may differ substantially between models.

Section 2 provides a description of the reanalysis models and data. Section 3 presents key aspects of the climatological mean diabatic heat budget in the tropical UTLS and describes the large differences in estimates of this budget according to different reanalyses. Section 4 discusses the sources and implications of some of the most pronounced differences among the reanalyses. Section 5 provides a summary of the current outlook.

\section{Data and methodology}

\subsection{Reanalysis data}

The Modern Era Retrospective Analysis for Research and Applications (MERRA) has been produced by NASA's Global Modeling and Assimilation Office (Rienecker et al., 2011). MERRA was conceived as a reanalysis of the satellite era (1979-present), with the primary objective of improving the representation of the water cycle relative to previous reanalyses. Diabatic heating is reported on a $1.25^{\circ} \times 1.25^{\circ}$ grid and includes components of heating due to long-wave radiation, short-wave radiation, moist physics, turbulent vertical mixing, gravity wave drag, and friction.

ERA-Interim (ERAI) is, like MERRA, a reanalysis of the satellite era (1979-present). ERAI has been produced by the European Centre for Medium-Range Weather Forecasts, and has been described in detail by Dee et al. (2011). We have interpolated the heating rates onto a $1^{\circ} \times 1^{\circ}$ horizontal grid with 60 isobaric levels that correspond to the nominal pressure of the eta levels used in the forecast model (relative to a surface pressure of $1000 \mathrm{hPa}$ ). Individual components of diabatic heating due to long-wave and short-wave radiative heating are provided; however, heating due to moist physics is not reported separately and must be inferred as a residual (see Fueglistaler et al., 2009b).

The Climate Forecast System Reanalysis (CFSR) was developed by the National Centers for Environmental Prediction (NCEP) as the first coupled atmosphere-ocean-land surface-sea ice reanalysis (Saha et al., 2010). CFSR technically only covers the period 1979-2009, but continuing output from the current (effectively identical) version of the Climate Forecast System model extends the CFSR data record to the present. Heating rates are provided on a $1^{\circ} \times 1^{\circ}$ horizontal grid with 37 isobaric levels. In addition to total diabatic heating rates, CFSR provides heating rates due to long-wave radiation, short-wave radiation, deep convection, shallow convection, large-scale condensation, and vertical diffusion.

The Japanese 25-yr Reanalysis (JRA) was initially commissioned to cover the period 1979-2004 (Onogi et al., 2007), but has since been extended to the present using the Japan Meteorological Agency (JMA) Climate Data Assimilation System. The diabatic heating rates used in this study are reported on a $2.5^{\circ} \times 2.5^{\circ}$ horizontal grid with 23 isobaric levels, and include components due to long-wave radiation, short-wave radiation, convection, large-scale condensation, and vertical diffusion.

The NCEP/NCAR Reanalysis 1 (NCEP) covers the period from 1948 to the present (Kalnay et al., 1996). NCEP was among the first reanalyses to be produced and remains one of the most widely used for scientific research. The NCEP diabatic heating data are provided as monthly means on the original T62 model grid with 28 sigma levels. We have interpolated these data to fixed pressure levels that match the nominal pressure of the sigma levels used in the forecast model 
(again relative to a surface pressure of $1000 \mathrm{hPa}$ ). The components of diabatic heating are identical to those reported by CFSR.

Table 1 provides an overview of the reanalysis forecast model frameworks, as well as key attributes of the radiation parameterisations. All of the diabatic heating rates used here are based exclusively on 6-h model forecasts except for the ERAI heating rates, which are based on 12-h model forecasts. The only observational constraint on reanalysis diabatic heating is the effect of the data assimilation on the forecast initial conditions.

\subsection{Physical context}

Diabatic heating is a fundamental component of the temperature budget, which may be expressed by the thermodynamic energy equation (terminology follows Equ. (3.58) of Peixoto and Oort, 1992):

$$
\frac{\partial T}{\partial t}+\mathbf{v} \cdot \nabla T-\omega\left(\frac{\kappa T}{p}-\frac{\partial T}{\partial p}\right)=\frac{Q}{c_{p}} .
$$

The terms on the left-hand side of Eq. (1) represent the change in temperature with time, horizontal advection of temperature, and vertical advection of temperature, respectively (see also Fueglistaler et al., 2009b). The term on the right-hand side represents diabatic heating, which can be separated into radiative and non-radiative components:

$$
\frac{Q}{c_{p}}=\frac{Q_{\mathrm{rad}}}{c_{p}}+\frac{Q_{\mathrm{res}}}{c_{p}} .
$$

Here, we refer to the non-radiative component $Q_{\text {res }}$ as the "residual" component of diabatic heating.

The radiative term can in turn be broken down in two ways, either as long-wave (LW) and short-wave (SW) radiative heating:

$$
\frac{Q_{\mathrm{rad}}}{c_{p}}=\frac{Q_{\mathrm{LW}}}{c_{p}}+\frac{Q_{\mathrm{SW}}}{c_{p}},
$$

or as clear-sky and cloud radiative heating

$$
\frac{Q_{\text {rad }}}{c_{p}}=\frac{Q_{\text {clear }}}{c_{p}}+\frac{Q_{\text {cloud }}}{c_{p}} \text {. }
$$

Clear-sky and cloud radiative heating can also be separated into LW and SW components. The distribution and magnitude of radiative heating depend on a number of other variables, including temperature, the concentrations of radiatively active trace gases (such as ozone and water vapour), and clouds. Figure 1 shows profiles of several of these variables averaged over the inner tropics $\left(10^{\circ} \mathrm{S}-10^{\circ} \mathrm{N}\right)$. For the purposes of understanding radiative heating it is necessary to consider both the temperatures generated by the forecast model (averaged over the forecast step prior to data assimilation; Fig. 1a) and the reanalysis temperatures (which include the effects of data assimilation; Fig. 1b). Assumptions regarding the distribution of ozone differ substantially among reanalyses. NCEP and ERAI use zonal and monthly mean climatologies, JRA uses daily profiles generated offline by a chemical transport model, and MERRA and CFSR use ozone concentrations simulated during the forecast step (see also Table 1). For context, Fig. 1c also shows climatological mean ozone profiles observed at 13 Southern Hemisphere Additional Ozonesonde (SHADOZ) stations in the tropics between 1998 and 2005 (Thompson et al., 2003; Fueglistaler and $\mathrm{Fu}, 2006$ ), as well as the ozone forecast produced by ERAI (which is not used in the radiative calculations). Cloud water content (Fig. 1d) is a product of the forecast model and is not affected by data assimilation. We will refer back to this figure where appropriate in the following discussion of differences in diabatic heating.

The residual heating term can likewise be separated into two main individual components:

$\frac{Q_{\text {res }}}{c_{p}}=\frac{Q_{\text {lat }}}{c_{p}}+\frac{Q_{\text {mix }}}{c_{p}}$,

where $Q_{\text {lat }}$ is latent heating due to moist physics and $Q_{\text {mix }}$ is heating due to turbulent mixing. The mixing term is one or more orders of magnitude smaller than the latent heating term in the time-mean zonal-mean perspective presented below, but local variations in this term can be as large as variations in the radiative or latent heating terms (Flannaghan and Fueglistaler, 2011)

The separation of diabatic terms described in this section provides a convenient mapping between diagnostics of diabatic heating and parameterisations of atmospheric physics, which can then be used for process evaluation in global models; however, not all terms are available for all reanalyses. Table 2 lists the terms in the diabatic heat budget provided by each of the reanalyses examined in this study.

\section{Climatological diabatic heat budgets}

The total diabatic heat budget and its major components are shown for each of the five reanalyses in Figs. 2-4. All quantities in these figures are averaged over the decade January 2001-January 2010. Figure 2 shows zonal mean distributions of total, radiative, and residual diabatic heating. Residual diabatic heating includes temperature tendencies due to all non-radiative physical processes, and is dominated by latent heating in the troposphere. Figure 3 shows the longitudinal distribution of total diabatic heating averaged over the inner tropics $\left(5^{\circ} \mathrm{S}\right.$ to $\left.5^{\circ} \mathrm{N}\right)$. The patterns are qualitatively similar (though more muted) when diabatic heating is averaged over $15^{\circ} \mathrm{S}$ to $15^{\circ} \mathrm{N}$ or $30^{\circ} \mathrm{S}$ to $30^{\circ} \mathrm{N}$. Figure 4 shows the zonal mean distributions of the long-wave (LW) and short-wave (SW) components of radiative heating. Differences among these five data sets are substantial throughout the UTLS, and are not limited to any one component of the diabatic heat budget. These differences show that the representations of 
Table 1. Attributes of the reanalysis forecast models and radiation parameterisations.

\begin{tabular}{|c|c|c|c|c|c|}
\hline & MERRA & ERAI & CFSR & JRA & NCEP \\
\hline Period & 1979-present & 1979-present & 1979-2011 & 1979-present & 1948-present \\
\hline Model grid & $(2 / 3)^{\circ} \times 0.5^{\circ}$ & $\mathrm{T}_{\mathrm{L}} 255$ & $\mathrm{~T} 382$ & T106 & T62 \\
\hline Model top & $0.01 \mathrm{hPa}$ & $0.1 \mathrm{hPa}$ & $\sim 0.266 \mathrm{hPa}$ & $0.4 \mathrm{hPa}$ & $\sim 3 \mathrm{hPa}$ \\
\hline Model levels & 72 & 60 & 64 & 40 & 28 \\
\hline $\mathrm{UTLS} \Delta z^{\mathrm{a}}$ & $\sim 1.1 \mathrm{~km}$ & $\sim 1.1 \mathrm{~km}$ & $\sim 0.88 \mathrm{~km}$ & $\sim 1.3 \mathrm{~km}$ & $\sim 1.8 \mathrm{~km}$ \\
\hline Heating from & 6-h forecast & 12-h forecast & 6-h forecast & 6-h forecast & 6-h forecast \\
\hline Long-wave ${ }^{b}$ & CLIRAD-LW & RRTM & RRTMG & JMA GSM & GFDL-IR \\
\hline Short-wave ${ }^{c}$ & CLIRAD-SW & 6-channel & RRTMG & CCM2 & GFDL-SW \\
\hline Cloud overlap & max/random & max/random & max/random & max/random & random \\
\hline $\mathrm{CO}_{2}$ & observed & fixed+trend & observed & fixed & fixed \\
\hline Ozone $^{\mathrm{d}}$ & prognostic & climatology & prognostic & offline CTM & climatology \\
\hline Aerosols & climatology & climatology & climatology & fixed & - \\
\hline Trace gases & climatology & fixed+trend & climatology & - & - \\
\hline
\end{tabular}

a Average vertical resolution between $\sim 200 \mathrm{hPa}$ and $\sim 50-60 \mathrm{hPa}$ (Fujiwara et al., 2012b).

b CLIRAD-LW has been described by Chou et al. (2001), RRTM by Mlawer et al. (1997), RRTMG by Clough et al. (2005), JMA GSM by Sugi et al. (1990), and GFDL-IR by Fels and Schwarzkopf (1975) and Schwarzkopf and Fels (1991).

c CLIRAD-SW has been described by Chou and Suarez (1999), the ERAI short-wave parameterisation by Fouquart and Bonnel (1980), RRTMG by Clough et al. (2005), CCM2 by Briegleb (1992), and GFDL-IR by Lacis and Hansen (1974).

$\mathrm{d}$ The MERRA and CFSR radiation schemes use ozone concentrations calculated by the forecast model. ERAI and NCEP use zonal and monthly mean climatologies (based on Fortuin and Langematz (1994), and Fels et al. (1980), respectively). The ozone concentrations used in JRA are produced daily as described by Onogi et al. (2007). See also Fig. 1c
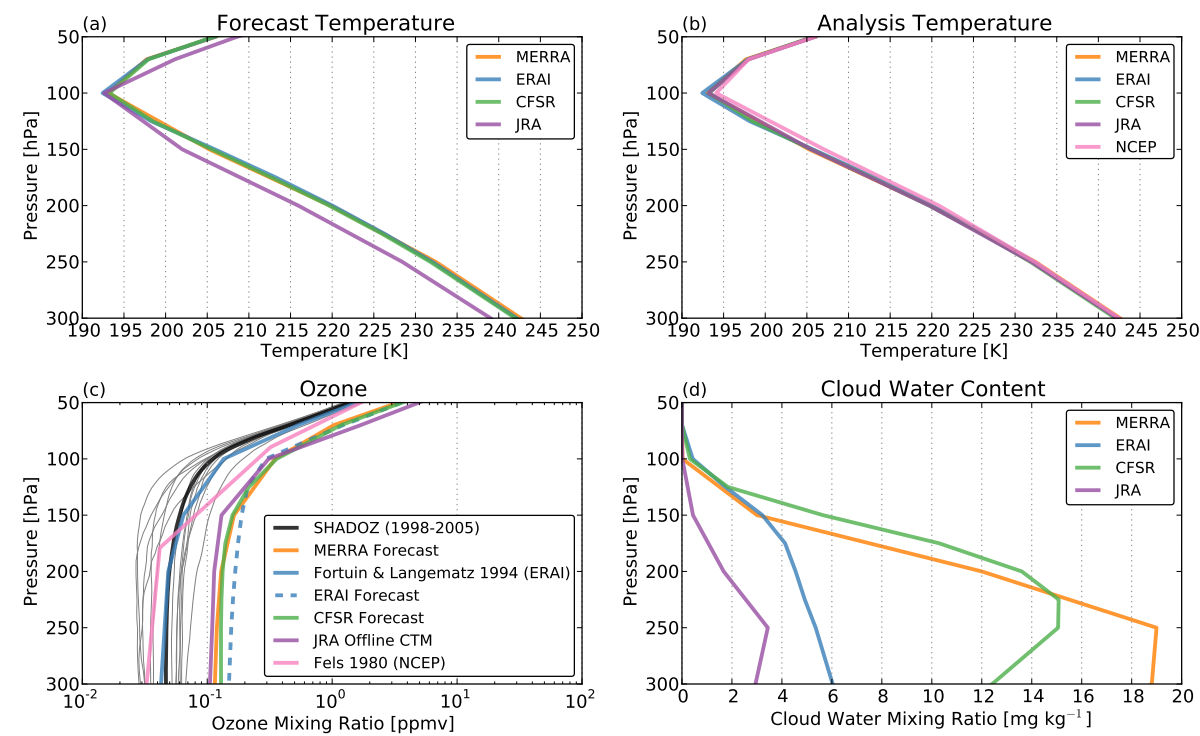

Fig. 1. Profiles of (a) forecast temperature (averaged over the forecast step prior to data assimilation), (b) analysis temperature (after data assimilation), (c) ozone mixing ratios, and (d) cloud water mixing ratios (combined ice and liquid water) averaged over the inner tropics $\left(10^{\circ} \mathrm{S}-10^{\circ} \mathrm{N}\right)$. Thick coloured lines indicate terms used in the reanalysis radiative transfer calculations. The dashed blue line in (c) indicates ozone concentrations simulated by the ERAI forecast model (which are not used in radiative calculations). The thick black line in (c) indicates the climatological mean ozone profile averaged from observations at 13 SHADOZ sites in the tropics between 1998 and 2005 (Thompson et al., 2003; Fueglistaler and Fu, 2006); thin grey lines indicate climatological mean profiles at individual SHADOZ sites.

physical processes in this region are remarkably different between the reanalysis atmospheric models, and imply the existence of substantial differences in tracer transport and mixing.

For convenience, we divide the diabatic heat budget into two vertical domains within the UTLS: the upper tropo- sphere (where latent heating is important) and the tropical tropopause layer and lower stratosphere (where latent heating largely disappears and the diabatic heat budget is dominated by radiative heating). The vertical boundary between these two domains is near $150 \mathrm{hPa}$ for all of the considered 

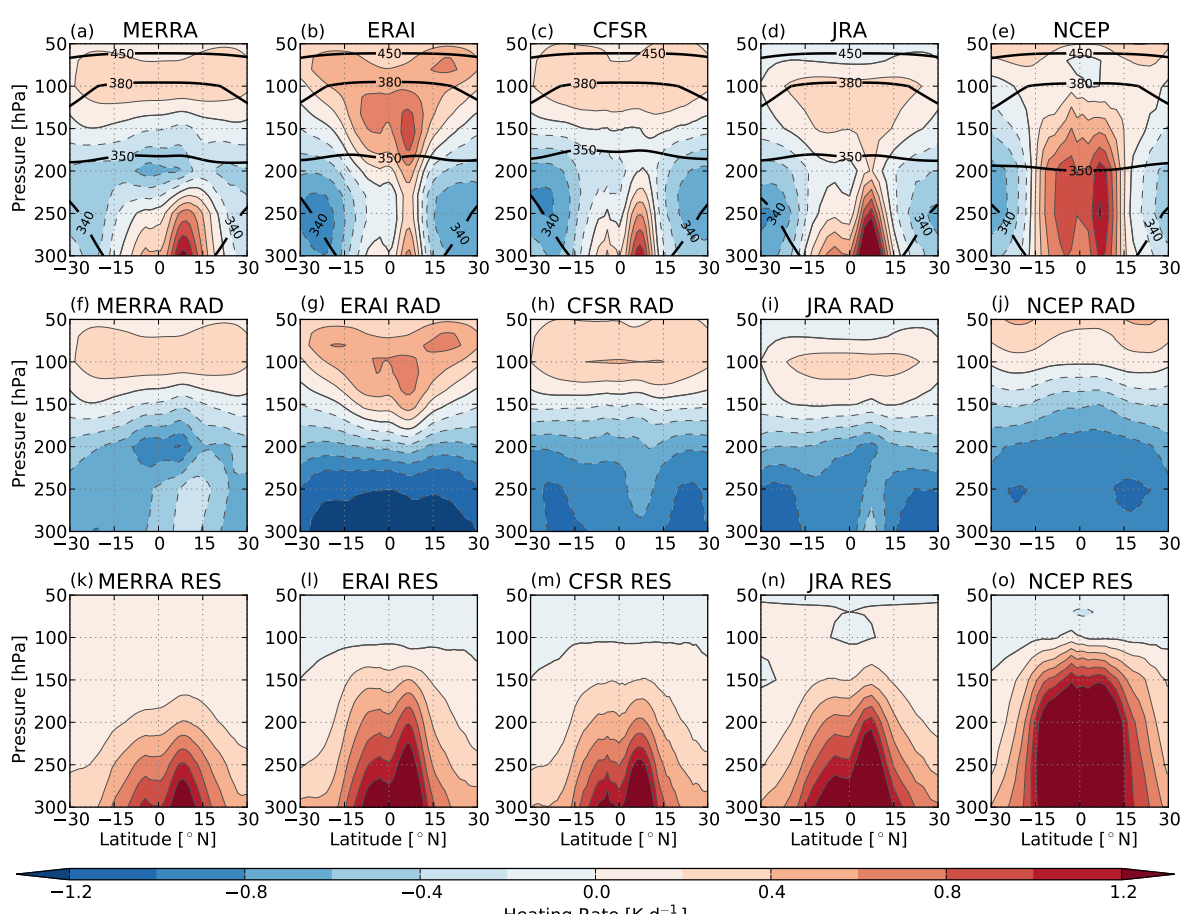

Heating Rate $\left[\mathrm{Kd}^{-1}\right]$

Fig. 2. Top row: zonal mean total diabatic heating averaged over the period 2001-2010 according to the (a) MERRA, (b) ERAI, (c) CFSR, (d) JRA, and (e) NCEP reanalysis data sets. The 340, 350, 380, and $450 \mathrm{~K}$ isentropic surfaces from each reanalysis are shown as black contours. Middle row: zonal mean radiative components of diabatic heating averaged over the period 2001-2010. Bottom row: zonal mean residual components of diabatic heating averaged over the period 2001-2010. Residual diabatic heating includes all diabatic heating due to non-radiative physics (moist physics, turbulent mixing, etc.).

Table 2. Availability of diabatic heating components for each reanalysis.

\begin{tabular}{cccccc}
\hline & MERRA & ERAI & CFSR & JRA & NCEP \\
\hline$Q_{\text {rad }}$ & $\checkmark$ & $\checkmark$ & $\checkmark$ & $\checkmark$ & $\checkmark$ \\
\hline$Q_{\text {LW }}$ & $\checkmark$ & $\checkmark$ & $\checkmark$ & $\checkmark$ & $\checkmark$ \\
$Q_{\text {SW }}$ & $\checkmark$ & $\checkmark$ & $\checkmark$ & $\checkmark$ & $\checkmark$ \\
$Q_{\text {clear }}$ & $\checkmark$ & $\checkmark$ & - & - & - \\
$Q_{\text {cloud }}$ & $\checkmark$ & $\checkmark$ & - & - & - \\
\hline$Q_{\text {res }}$ & $\checkmark$ & $\checkmark$ & $\checkmark$ & $\checkmark$ & $\checkmark$ \\
\hline$Q_{\text {lat }}$ & $\checkmark$ & - & $\checkmark$ & $\checkmark$ & $\checkmark$ \\
$Q_{\text {mix }}$ & $\checkmark$ & - & $\checkmark$ & $\checkmark$ & $\checkmark$ \\
\hline
\end{tabular}

reanalyses but NCEP, for which the boundary is approximately $100 \mathrm{hPa}$.

\subsection{The upper troposphere}

The upper part of the overturning Hadley circulation is readily apparent between 300 and $150 \mathrm{hPa}$ in the zonal mean diabatic heat budget (Fig. 2). Diabatic heating indicates an upward mass flux in potential temperature coordinates, while diabatic cooling indicates a downward mass flux. Surfaces of constant potential temperature roughly coincide with surfaces of constant pressure in the tropical UTLS, particularly in the inner tropics, so that regions of diabatic heating generally indicate regions of climatological mean ascent in pressure coordinates as well. In the context of the Hadley circulation, latent heating in the UT (predominantly associated with deep convection) is balanced by radiative cooling. Deep convection preferentially occurs in the inner tropics, leading (in a time-mean zonal-mean sense) to diabatic ascent over the inner tropics and diabatic descent over the subtropics.

Two peaks in tropical heating (located near $5^{\circ} \mathrm{S}$ and between 5 and $10^{\circ} \mathrm{N}$ ) are identifiable in both the total and residual diabatic heating fields. These peaks correspond to seasonal shifts in the zonal mean location of the ascending branch of the Hadley cell, or intertropical convergence zone (ITCZ). The locations of these maxima are consistent among the reanalyses; however, the horizontal extent, vertical depth, and magnitude of zonal mean heating differ considerably, especially with respect to net diabatic heating. For example, MERRA indicates that the maximum in net diabatic heating in the inner tropics is relatively broad in horizontal extent but shallow in vertical extent, whereas ERAI indicates that it is weaker and narrower. The vertical extent of total heating associated with the ascending branch of the Hadley cell is also relatively shallow in ERAI, with a local minimum in heating 

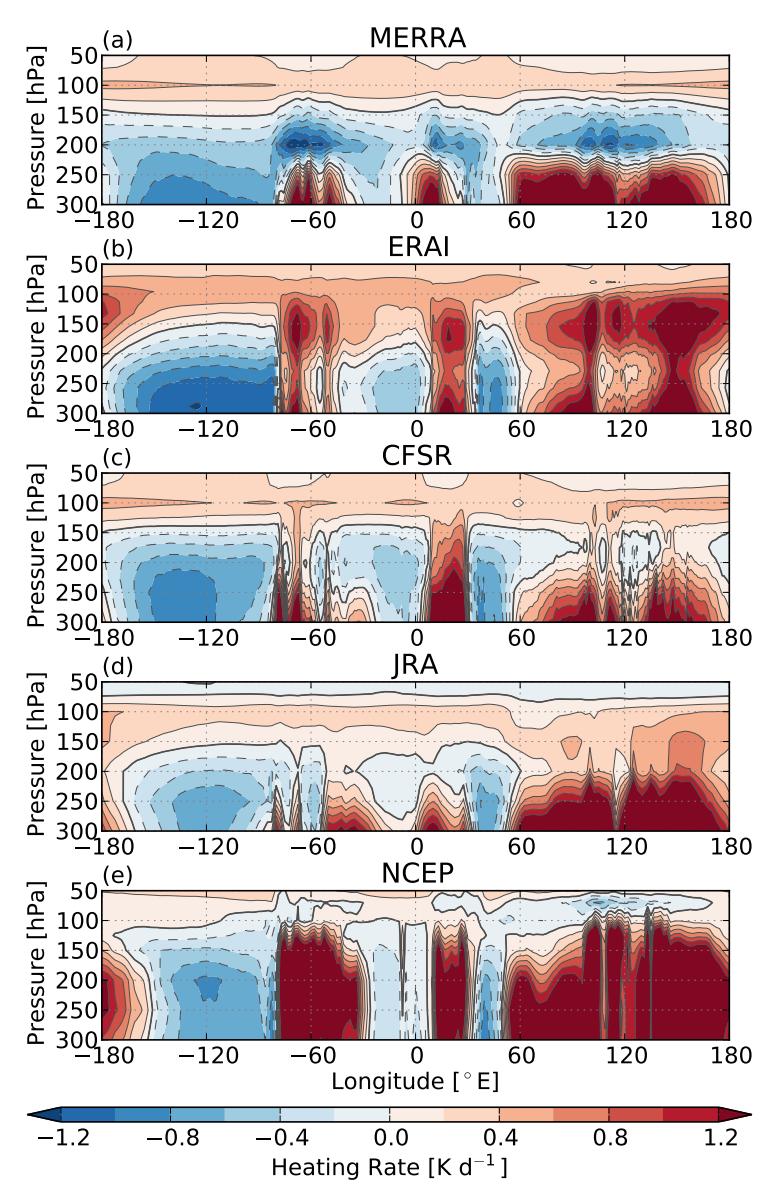

Fig. 3. Longitude-pressure distributions of diabatic heating averaged over $5^{\circ} \mathrm{S}$ to $5^{\circ} \mathrm{N}$ for the period 2001-2010.

near $250 \mathrm{hPa}$ rather than $200 \mathrm{hPa}$ (as in MERRA, CFSR, and JRA) or $100 \mathrm{hPa}$ (as in NCEP). It is remarkable that the climatological mean heating in this region is weakest in ERAI given that the residual heating (dominated by latent heat release) is stronger in ERAI than MERRA or CFSR (Fig. 2, bottom panels). This situation arises because radiative cooling is also much stronger in ERAI (Fig. 2, middle panels), potentially due to differences in ozone concentrations in the upper troposphere (see Fig. 1c and discussion in Sect. 4).

The CFSR and JRA zonal mean diabatic heat budgets are qualitatively similar below $200 \mathrm{hPa}$ : net heating in the inner tropics is narrower than MERRA but broader than ERAI, while radiative cooling is stronger than MERRA but weaker than ERAI. Quantitative differences between these two reanalyses are difficult to evaluate given differences in the spatial resolution of the data used to produce these figures $\left(1^{\circ}\right.$ for CFSR compared to $2.5^{\circ}$ for JRA). The radiative heat budget of NCEP is similar to that of the other reanalyses in the upper troposphere, but the residual diabatic heating is much larger and extends higher (up to about $100 \mathrm{hPa}$ ) than in any other reanalysis.
Net diabatic cooling prevails throughout the zonal mean tropics in MERRA and CFSR between $\sim 200 \mathrm{hPa}$ and $\sim 150 \mathrm{hPa}$. The extratropics do not provide a net diabatic heat source at these pressure levels either (see, e.g. Ling and Zhang, 2013, their Fig. 5). Although diabatic heating rates need not balance upon global averaging (as cross-isentropic mass fluxes must do), the presence of pressure surfaces with net negative heating rates everywhere indicates a deficit in the model's diabatic heat budget. This type of deficit may be corrected during the assimilation increment (the incremental adjustment of forecast temperatures during the data assimilation step; see, e.g. Fueglistaler et al., 2009b); however, simulations of atmospheric transport driven by these heating rates will encounter a vertical "transport barrier". This layer of zonal mean diabatic cooling persists year-round in MERRA monthly means (not shown). Seasonally-varying regions of diabatic ascent connect the tropical UT to the tropical LS in each of the other four reanalyses, including CFSR.

Just as the zonal mean distribution of diabatic heating in the tropical UTLS is strongly tied to the Hadley circulation, the longitudinal distribution is strongly tied to the equatorial Walker circulation (Fig. 3). Regions of net diabatic heating are located in the well-known equatorial convective regions over South America (near $60^{\circ} \mathrm{W}$ ), western and central Africa (near $20^{\circ} \mathrm{E}$ ), and the maritime continent (centered near $120^{\circ} \mathrm{E}$ ). Conversely, the absence of convection over the eastern Pacific within $5^{\circ} \mathrm{S}-5^{\circ} \mathrm{N}$ leads to strong net subsidence. These geographical distinctions in the net diabatic heating field extend upward to approximately $150 \mathrm{hPa}$ in ERAI, CFSR, and JRA and up to approximately $100 \mathrm{hPa}$ in NCEP; however, the regions of UT heating are capped by strong net diabatic cooling at $200 \mathrm{hPa}$ in MERRA. In fact, the meridional distribution of net diabatic heating at $200 \mathrm{hPa}$ in MERRA is qualitatively opposite to that in ERAI, CFSR, JRA, or NCEP: tropical deep convective regions represent local minima in $200 \mathrm{hPa}$ diabatic heating in MERRA but maxima in the other four reanalyses, while tropical subsidence zones represent local maxima in MERRA (although net heating is still negative) but minima in the other four reanalyses.

The time-mean transport barrier in MERRA appears to arise from a combination of two factors. First, the vertical extent of latent heating associated with moist convection appears to be considerably shallower in MERRA than in the other four reanalyses (see, e.g. the residual heating distribution shown in Fig. 2k relative to those shown in Fig. 2lo). Second, there is a pronounced local maximum in UT radiative cooling at $200 \mathrm{hPa}$. This maximum is centered over the Equator, directly above the peak latent heating associated with the ascending branch of the Hadley circulation, and is consistent with the maxima located over the ascending branches of the meridional Walker circulation. This distribution of radiative heating is unique to MERRA among the five reanalyses, and appears to be related primarily to LW radiative transfer (Fig. 4a). We will return to this topic in Sect. 4. 

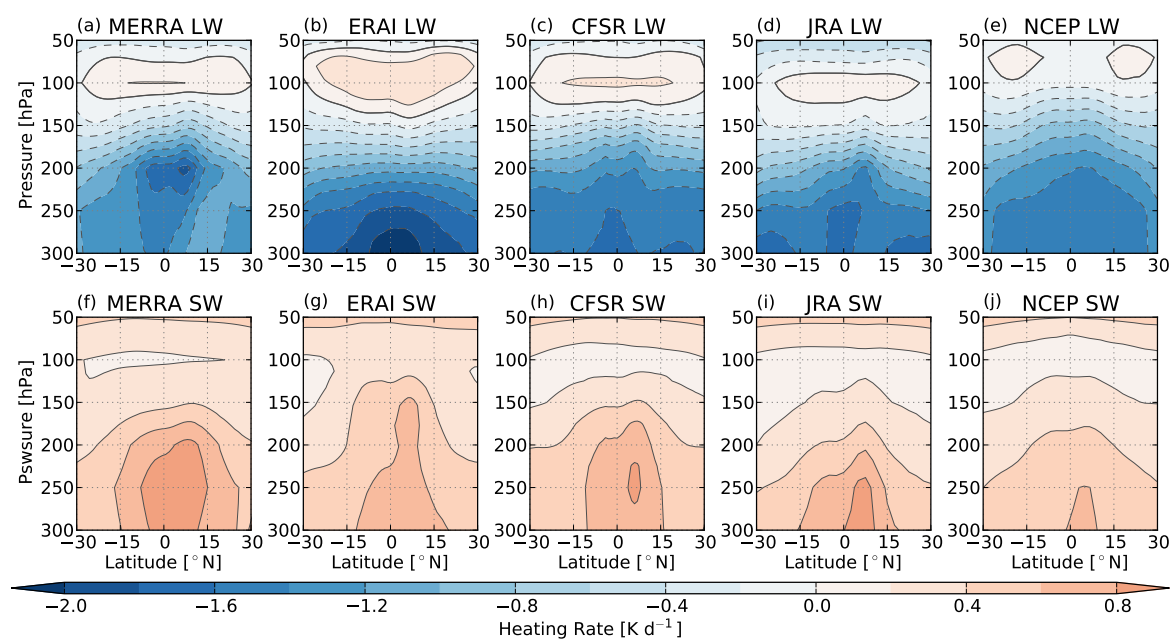

Fig. 4. Zonal mean (a)-(e) long-wave and (f)-(j) short-wave components of radiative diabatic heating averaged over the period 2001-2010.

The distributions of SW radiative heating in the UT (Fig. 4f-j) are consistent with the hypothesis that these distributions arise from SW cloud radiative heating, which in this region is dominated by radiative heating associated with clouds of convective origin. This relationship can be deduced from the similarity between the zonal mean patterns of SW radiative heating and residual heating (Fig. $2 \mathrm{k}-\mathrm{o}$ ), the latter of which is dominated by deep convective latent heating. This suggests that differences in the distribution of SW radiative heating in this region are largely attributable to differences in model simulations of deep convection and the associated clouds, which are disturbingly large (Fig. 1d).

\subsection{The tropical tropopause layer and lower stratosphere}

The non-radiative diabatic heating terms are small above approximately $150 \mathrm{hPa}$ in all reanalyses, with the notable exception of NCEP (where residual diabatic heating is large up to about $100 \mathrm{hPa}$ ). As expected, this shift in the dominant component of net diabatic heating roughly coincides with the level of zero net radiative heating (LZRH) in each reanalysis (see Fig. 4). The vertical location of the LZRH in pressure is largely consistent among the reanalyses (again with the exception of NCEP), but its zonal structure varies considerably. The LZRH is higher in the inner tropics than in the subtropics in MERRA and NCEP, whereas it is lower in the inner tropics than in the subtropics in ERAI and roughly isobaric in CFSR and JRA.

The meridional structure of the inner-tropical total diabatic heat budget in the TTL/LS is qualitatively similar among the reanalyses (Fig. 3); however, the zonal mean structure (Fig. 2) reveals differences that are important in the context of the forcing of tropical upwelling. In particular, ERAI shows a pronounced $\mathrm{v}$-shaped structure of maximum heating rates, with maxima in the inner tropics below $100 \mathrm{hPa}$ and in both subtropics near $70 \mathrm{hPa}$. This $\mathrm{v}$-shaped structure is much less apparent in the other reanalyses, which simulate only weak local maxima in the subtropics near $70 \mathrm{hPa}$. These differences in the distribution of diabatic heating imply differences in the strength of upwelling in the inner tropics relative to upwelling in the subtropics, which in turn imply differences in the distribution of wave drag and the stratospheric overturning circulation (see, e.g. Plumb and Eluszkiewicz, 1999).

Figure 4 shows that many of the differences in the structure of the net diabatic heat budget in the TTL and LS arise from differences in long-wave radiative heating, which is strongest (most positive) in ERAI and weakest in JRA and NCEP. Long-wave radiative heating in this layer is strongly affected by temperature (with lower temperatures likely resulting in stronger radiative heating and vice versa; see discussion by Fueglistaler et al., 2009b) and ozone. The differences in radiative heating are consistent with known temperature biases in ERAI (which is somewhat cold-biased; see Fueglistaler et al., 2013) and NCEP (which is somewhat warm-biased, particularly over the maritime continent; see Pawson and Fiorino, 1998). The magnitudes of these temperature biases may change over time as the set of data assimilated during the analysis step changes; however, their relative signs are consistent when averaged over the 2001-2010 analysis period (Fig. 1a and b). Biases in tropical mean analysis temperatures are largest near $100 \mathrm{hPa}$, where NCEP is approximately $1.5 \mathrm{~K}$ warmer than ERAI and approximately $1 \mathrm{~K}$ warmer than MERRA, CFSR and JRA during this period.

For ozone the situation is more complex: both ERAI and NCEP use zonal-mean monthly-mean climatologies, while MERRA and CFSR use prognostic ozone simulated by the underlying forecast model and JRA uses daily offline calculations. None of these estimates adequately resolves the sharp gradients in ozone concentration in this layer (Fig. 1c). 
The climatologies used by NCEP and ERAI are in better agreement with SHADOZ observations in the tropical mean, but are by definition incapable of representing the geographic differences evident in the range of climatological mean profiles observed at individual SHADOZ sites. The model estimates of tropical mean ozone concentrations used by MERRA, CFSR, and JRA are all significantly larger than those observed during the SHADOZ campaign throughout the tropical UTLS.

Net diabatic heating rates in JRA are negative throughout much of the tropics between about 60 and $40 \mathrm{hPa}$ (upper level not visible in Figs. 2-4), primarily due to a lack of LW heating in this layer relative to the other reanalyses (Fig. 4d). This layer of time-mean net diabatic cooling is again physically unrealistic. Moreover, it contradicts the generally accepted view of the stratospheric residual circulation, in which diabatic descent (cooling) over the extratropics is balanced by diabatic ascent (heating) at low latitudes. The temperature profile produced by the JRA forecast model has a large warm bias in the lower stratosphere relative to the other reanalyses (Fig. 1a), consistent with stronger LW cooling. Positive LW heating in JRA is restricted to the immediate vicinity of the $100 \mathrm{hPa}$ level (where temperatures are comparable with those simulated by the other forecast models) but rapidly transitions to strong LW cooling above (where tropical mean temperatures are more than $3 \mathrm{~K}$ warmer than those simulated by the other forecast models). These temperature biases may be related to known deficiencies in the JRA radiation scheme (Onogi et al., 2007). JMA has recently developed a new 55-year reanalysis system, which is scheduled for release at the beginning of October 2013. This new reanalysis system includes substantial improvements to the radiation scheme that appear to largely eliminate earlier cold biases in JRA-25 analysis temperatures in the lower stratosphere (Ebita et al., 2011). These improvements may also bring the stratospheric diabatic heat budget more in line with both expectations and other reanalyses. In the meantime, users of stratospheric diabatic heating rates from JRA25/JCDAS should be aware of this difference between JRA and other reanalyses.

\section{Discussion}

The results presented in Sect. 3 indicate that the differences in the diabatic heating rates (and consequently the corresponding circulations) among the reanalyses are large. These differences arise in part due to differences in the models' representations of tropical deep convection, which is widely recognised as a challenge for global-scale models. The substantial differences in the radiative heating rates may be more of a surprise, and warrant a more detailed analysis.

Radiative heating rates in the $300 \mathrm{hPa}$ to $100 \mathrm{hPa}$ layer are particularly different between MERRA and ERAI (see Fig. 2, middle panel). These differences exist in both LW and SW
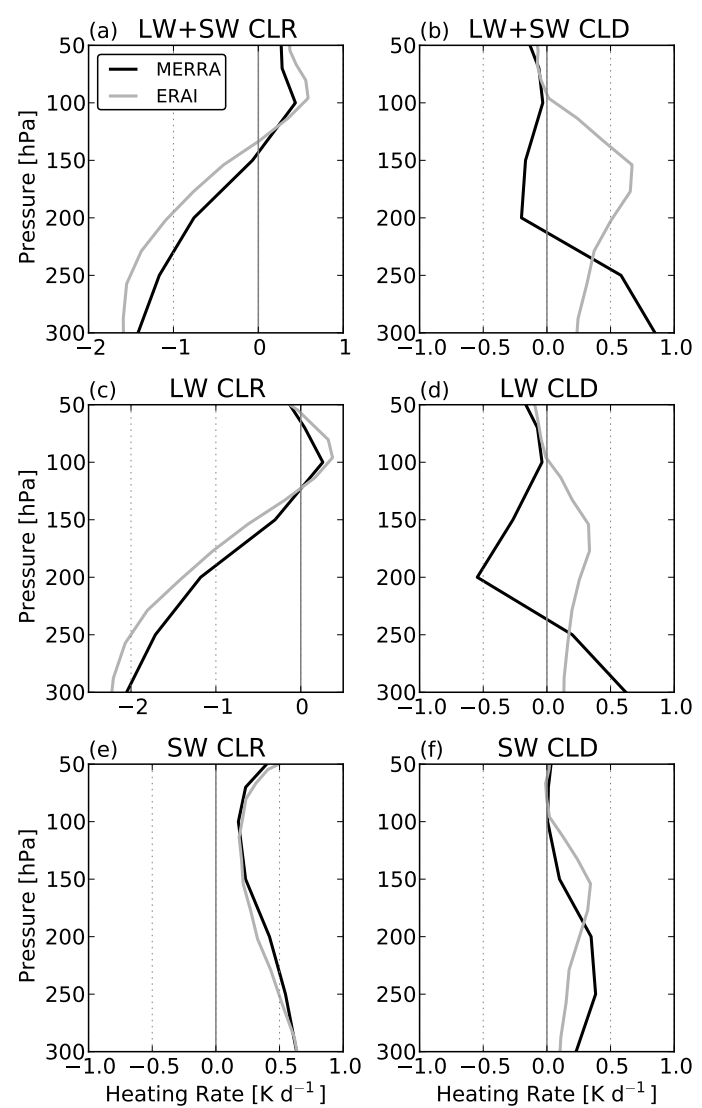

Fig. 5. Profiles of clear-sky (left column) and cloud (right column) radiative heating rates for (a)-(b) long-wave plus short-wave, (c)-(d) long-wave, and (e)-(f) short-wave radiation according to MERRA (black line) and ERAI (grey line). Cloud radiative heating rates are calculated as all-sky minus clear-sky. Profile values have been averaged over $5^{\circ} \mathrm{S}$ to $5^{\circ} \mathrm{N}$ for the period 2001-2004.

radiation (see Fig. 4). Figure 5 shows profiles of clear-sky radiative heating and the radiative effects of clouds averaged over the inner tropics $\left(5^{\circ} \mathrm{S}-5^{\circ} \mathrm{N}\right)$ for MERRA and ERAI. Clear-sky radiative heating is larger in MERRA than in ERAI in the upper troposphere, particularly below $150 \mathrm{hPa}$, while the opposite is true above $150 \mathrm{hPa}$. These differences result in a slight offset in the vertical location of the clear-sky level of zero radiative heating, which could have important implications for simulations of transport within the TTL using these reanalyses (Fueglistaler et al., 2009a). Differences in the distributions of ozone used for the radiative transfer calculations may be at least partially responsible for the differences in clear-sky radiative heating. The concentrations of ozone simulated by the MERRA forecast model are considerably higher than the climatology used by ERAI, particularly in the upper troposphere (Fig. 1c). Ozone has absorption bands in both the LW and SW parts of the spectrum, so that larger concentrations of ozone may enhance both LW and SW heating in the troposphere. The difference in clear-sky radiative heating in the lower stratosphere is more complicated, with 
possible contributions from biases in temperature (tropical mean temperatures at $100 \mathrm{hPa}$ are $0.5-1 \mathrm{~K}$ colder in ERAI than in MERRA) or ozone (like carbon dioxide, larger concentrations of ozone in the lower stratosphere may enhance local LW radiative cooling, while larger concentrations of ozone higher in the stratosphere may reduce SW heating in the lower stratosphere by reducing the available flux of solar radiation in ozone absorption bands). A more complete diagnosis would require detailed radiative calculations using full atmospheric profiles, and is beyond the scope of this work.

Although these differences in clear-sky radiative heating are potentially significant (particularly with respect to the location of the LZRH), it is evident that the largest differences in tropical radiative heating rates arise from differences in the radiative impacts of clouds. Cloud SW heating is greater in MERRA than in ERAI from about 300 to $200 \mathrm{hPa}$, but the opposite is true between 200 and $100 \mathrm{hPa}$. Similarly, cloud LW heating in MERRA is greater than that in ERAI below $250 \mathrm{hPa}$, while cloud LW heating in ERAI is greater than that in MERRA (which is in fact negative) between 250 and $100 \mathrm{hPa}$. These differences are most pronounced in the inner tropics (where cloud occurrence frequency is largest), but the profiles are qualitatively similar when averaged over the entire study domain $\left(30^{\circ} \mathrm{S}-30^{\circ} \mathrm{N}\right.$; not shown).

Fueglistaler and $\mathrm{Fu}$ (2006) and Mcfarlane et al. (2007) calculated the impacts of clouds on radiative heating in the UTLS based on Atmospheric Radiation Measurement (ARM) program observations at two sites in the tropical western Pacific (see also comparison with ERAI by Fueglistaler et al., 2009b). Their calculations showed that cloud impacts on net radiative heating at these two sites were positive up to about $125 \mathrm{hPa}$. They also showed that peak net cloud radiative heating was shifted upward in several model estimates (including ERAI) relative to the ARM-based profiles; however, the inability of the ARM millimeter cloud radar to resolve optically-thin cirrus clouds introduces large uncertainties in comparisons above $200 \mathrm{hPa}$.

Yang et al. (2010) used a detailed radiative transfer model and observations of atmospheric composition and clouds (including thin cirrus) to calculate cloud radiative heating in the UTLS between $30^{\circ} \mathrm{S}$ and $30^{\circ} \mathrm{N}$. Their calculations indicate that the impact of clouds on net radiative heating is positive below $100 \mathrm{hPa}$ and negative above $100 \mathrm{hPa}$, with a positive SW cloud influence throughout the UTLS (peaking near $150 \mathrm{hPa}$ ) and a LW cloud influence that transitions from positive below $\sim 165 \mathrm{hPa}$ to negative above. The SW radiative effect of clouds in the UTLS in ERAI is similar to that derived by Yang et al. (2010); however, the LW cloud radiative heating is smaller below $200 \mathrm{hPa}$ and larger above $200 \mathrm{hPa}$. The MERRA cloud radiative forcing qualitatively resembles that reported by Yang et al. (2010), but with peak SW cloud forcing shifted downward by $\sim 100 \mathrm{hPa}$ and the transition from positive to negative LW cloud forcing shifted downward by $\sim 50 \mathrm{hPa}$. Moreover, the maximum in cloud LW cooling is quantitatively much stronger in MERRA. These differences

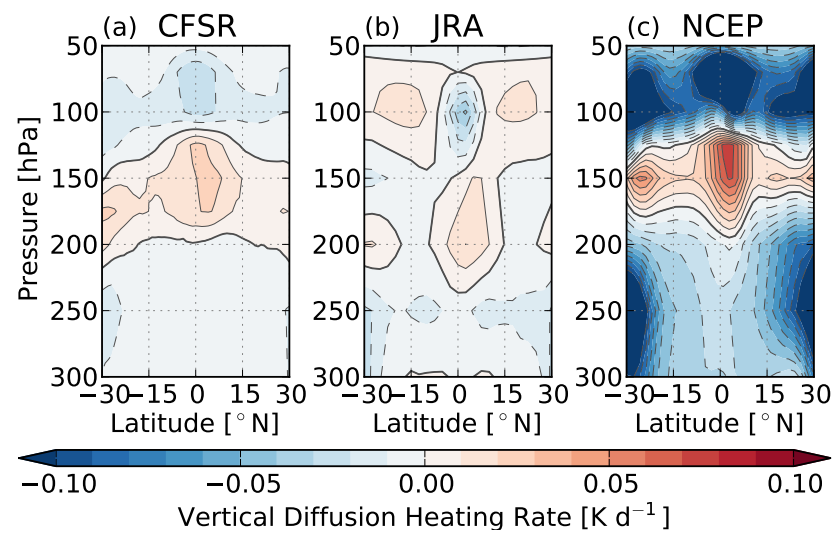

Fig. 6. Zonal mean heating due to parameterised turbulent mixing in (a) CFSR, (b) JRA, and (c) NCEP.

lead to a mismatch in the sign of the net cloud radiative forcing between MERRA and the other two estimates in the layer between 200 and $100 \mathrm{hPa}$.

Simulations of cloud water content are very different between MERRA and ERAI (Fig. 1d), possibly reflecting different approaches to the treatment of convective anvil clouds. These discrepancies hint at explanations for why estimates of diabatic heating in the tropical upper troposphere differ so much between these two reanalyses. A full examination of how these differences in cloud water content interact with the model radiation schemes is beyond the scope of this paper and will be explored in future work.

In addition to latent heating and radiative heating, parameterised mixing contributes to the diabatic heat budgets of reanalyses. This term is generally about an order of magnitude smaller than the other terms and is often ignored; however, local variations in this term can be as large as variations in the radiative terms (see also Flannaghan and Fueglistaler, 2011). The physical realism of these terms is often questionable, as the mixing parameterisations are poorly constrained by observations and are often used to "tune" the model or compensate for errors in other aspects of the model formulation.

Figure 6 shows zonal mean time mean diabatic tendencies from parameterised mixing in CFSR, JRA, and NCEP. MERRA also provides a temperature tendency due to turbulent mixing; however, this term is approximately three orders of magnitude smaller than the radiative and latent heating components and we have therefore chosen to omit it. ERAI does not provide separate moist physics and vertical mixing terms, though turbulent mixing due to shear-flow instability can be inferred from offline calculations (Flannaghan and Fueglistaler, 2011). Diabatic heating from parameterised mixing is much larger in NCEP than in the other reanalyses, with strong cooling between 100 and $50 \mathrm{hPa}$ and strong warming between 200 and $100 \mathrm{hPa}$. This pattern implies substantial mixing of the upper troposphere with the 
lower stratosphere. The pattern in CFSR is similar to that in NCEP, but weaker in amplitude. Both models use a similar vertical diffusion scheme in the free atmosphere, but the diffusion coefficient in CFSR decreases exponentially with pressure while that in NCEP remains constant. The relative strength of the turbulent heating in NCEP reinforces many of the unique features of the NCEP net diabatic heat budget, such as the greater vertical depth of the residual component and the cooling located immediately above the tropopause in the inner tropics. The pattern in JRA is similar in the inner tropics, but contains a weak warming near $100 \mathrm{hPa}$ in the subtropics that is not seen in the other reanalyses.

It is certainly interesting from the perspective of troposphere-stratosphere exchange that all three reanalyses show local maxima in parameterised turbulent mixing across the tropical tropopause. Flannaghan and Fueglistaler (2011) have shown that different formulations of mixing parameterisations may activate in response to different physical processes. In light of known challenges in reconciling temperature observations and general circulation model results in this layer (e.g. Fu et al., 2011; Seidel et al., 2012), it may be worthwhile to analyse the mixing terms in climate model simulations.

\section{Conclusions and outlook}

We have compared the diabatic heat budgets of the tropical UTLS as simulated by five widely-used reanalysis models. The differences in the distributions of net diabatic heating are large, as are the differences in the individual terms. These differences highlight the significant uncertainties that remain in the processes that control the heat budget in the tropical UTLS, and have important implications for understanding transport and mixing in this layer. For example, the distribution of diabatic heating in the UT has implications for the transport of tracers from the surface to the stratosphere, while the magnitude of radiative heating in the stratosphere is important for transport and composition in the global stratosphere.

Tracer transport from the surface to the stratosphere typically occurs in two stages: rapid vertical transport from the surface to the UT or TTL in deep convection, followed by slow ascent into the stratosphere. Convection may also penetrate the stratosphere directly, but the impact of this very deep convection on the heat balance remains poorly quantified. As mentioned above, the existence of net diabatic cooling directly above deep convective regions in MERRA represents a barrier to transport into the TTL and LS. Bergman et al. (2013) compared estimates of vertical transport in the Asian monsoon region during boreal summer based on MERRA with estimates based on high-resolution operational analyses from ECMWF and NCEP. They reported that MERRA drastically underestimates vertical transport between $200 \mathrm{hPa}$ and $100 \mathrm{hPa}$ relative to the other data sets. This difference is particularly pronounced when MERRA diabatic heating is used to estimate vertical motion (rather than kinematic vertical velocity). By contrast, the strong net diabatic heating directly above convective regions in ERAI suggests that vertical transport from the surface to the LS may be particularly efficient in ERAI, with ascent through the TTL potentially occurring much more rapidly than in the other reanalyses. As discussed in Sect. 4, these differences between MERRA and ERAI are at least partially attributable to differences in simulations of clouds and their radiative impacts in the UTLS. These differences will be explored more fully in future work.

Schoeberl et al. (2012) used winds and heating rates from MERRA, ERAI, and CFSR to drive ensembles of Lagrangian trajectories in the global stratosphere. They then used these trajectories to study interannual variability and trends in stratospheric water vapour over the period 1979-2010. Comparing the results to satellite observations, they reported that rates of vertical ascent in the tropical LS are approximately $30 \%$ too fast when based on ERAI, close to observed when based on CFSR, and approximately $15 \%$ too slow when based on MERRA. These differences in vertical ascent are apparent in the relative strengths of diabatic heating in the LS (Fig. 2), particularly in the LW radiative component (Fig. 4). We will explore the effects of differences in reanalysis diabatic heat budgets on transport and mixing in the tropical UTLS in a follow-up publication.

The diabatic heat budget provides an additional perspective and physical constraint for process evaluation and studies of global change. We stress that more attention should be paid to this budget and its individual terms in the future, and therefore welcome the recent establishment of the Stratospheric Processes and their Role in Climate (SPARC) Renalysis/analysis Intercomparison Project (S-RIP) (Fujiwara et al., 2012a; Fujiwara and Jackson, 2013).

Acknowledgements. This research was supported in part by the EU-funded SHIVA project and by Tsinghua University. MERRA reanalysis data were provided by the NASA GES DISC. Access to the ERAI reanalysis data was provided by the NERC BADC and ECMWF. CFSR and NCEP reanalysis data were obtained from the CISL RDA at NCAR. JRA reanalysis data were provided by the JMA and CRIEPI. We extend particular thanks to David Tan at ECMWF, Craig Long and Yu-Tai Hou at NOAA, Michael Bosilovich at NASA, and Kazutoshi Onogi at JMA for their assistance in tracking down details of the reanalysis data sets, and thank the editor and two anonymous reviewers for their contributions.

Edited by: F. Fierli 


\section{References}

Bergman, J. W., Fierli, F., Jensen, E. J., Honomichl, S., and Pan, L. L.: Boundary layer sources for the Asian anticyclone: regional contributions to a vertical conduit, J. Geophys. Res., 118, 25602575, doi:10.1002/jgrd.50142, 2013.

Briegleb, B. P.: Delta Eddington approximation for solar radiation in the NCAR Community Climate Model, J. Geophys. Res., 97, 7603-7612, 1992.

Chou, M.-D. and Suarez, M. J.: A solar radiation parameterization for atmospheric studies, NASA/TM-1999-104606, 15, 40 pp., 1999.

Chou, M.-D., Suarez, M. J., Liang, X. Z., and Yan, M. M.-H.: A thermal infrared radiation parameterization for atmospheric studies, NASA/TM-2001-104606, 19, 56 pp., 2001.

Clough, S. A., Shephard, M. W., Mlawer, E. J., Delamere, J. S., Iacono, M. J., Cady-Pereira, K., Boukabara, S., and Brown, P. D.: Atmospheric radiative transfer modeling: a summary of the AER codes, J. Quant. Spectrosc. Radiat. Transf., 91, 233-244, 2005.

Dee, D. P., Uppala, S. M., Simmons, A. J., Berrisford, P., Poli, P., Kobayashi, S., Andrae, U., Balmaseda, M. A., Balsamo, G., Bauer, P., Bechtold, P., Beljaars, A. C. M., van de Berg, L., Bidlot, J., Bormann, N., Delsol, C., Dragani, R., Fuentes, M., Geer, A. J., Haimberger, L., Healy, S. B., Hersbach, H., Hólm, E. V., Isaksen, L., Kållberg, P., Köhler, M., Matricardi, M., McNally, A. P., Monge-Sanz, B. M., Morcrette, J.-J., Park, B.-K., Peubey, C., de Rosnay, P., Tavolato, C., Thépaut, J.-N., and Vitart, F.: The ERA-Interim reanalysis: configuration and performance of the data assimilation system, Q. J. Roy. Meteor. Soc., 137, 553-597, doi:10.1002/qj.828, 2011.

Ebita, A., Kobayashi, S., Ota, Y., Moriya, M., Kumabe, R., Onogi, K., Harada, Y., Yasui, S., Miyaoka, K., Takahashi, K., Kamahori, H., Kobayashi, C., Endo, H., Soma, M., Oikawa, Y., and Ishimizu, T.: The Japanese 55-year Reanalysis "JRA-55": An interim report, SOLA, 7, 149-152, doi:10.2151/sola.2011-038, 2011.

Fels, S. and Schwarzkopf, M. D.: The simplified exchange approximation: a new method for radiative transfer calculations, J. Atmos. Sci., 32, 1475-1488, 1975.

Fels, S. B., Mahlman, J. D., Schwarzkopf, M. D., and Sinclair, R. W.: Stratospheric sensitivity to perturbations in ozone and carbon dioxide: Radiative and dynamical response, J. Atmos. Sci., 37, 2265-2297, 1980.

Flannaghan, T. J. and Fueglistaler, S.: Kelvin waves and shear-flow turbulent mixing in the TTL in (re-)analysis data, Geophys. Res. Lett., 38, L02801, doi:10.1029/2010GL045524, 2011.

Fortuin, J. P. and Langematz, U.: An update on the current ozone climatology and on concurrent ozone and temperature trends, Proc. SPIE, 2311, 207-216, doi:10.1117/12.198578, 1994.

Fouquart, Y. and Bonnel, B.: Computation of solar heating of the Earth's atmosphere: a new parameterization, Beitr. Phys., 53, 3562, 1980.

$\mathrm{Fu}$, Q., Manabe, S., and Johanson, C. M.: On the warming in the tropical upper troposphere: Models versus observations, Geophys. Res. Lett., 38, L15704, doi:10.1029/2011GL048101, 2011.

Fueglistaler, S. and Fu, Q.: Impact of clouds on radiative heating rates in the tropical lower stratosphere, J. Geophys. Res., 111, D23202, doi:10.1029/2006JD007273, 2006.
Fueglistaler, S., Dessler, A. E., Dunkerton, T. J., Folkins, I., Fu, Q., and Mote, P. W.: Tropical tropopause layer, Rev. Geophys., 47, RG1004, doi:10.1029/2008RG000267, 2009a.

Fueglistaler, S., Legras, B., Beljaars, A., Morcrette, J.-J., Simmons, A., Tompkins, A. M., and Uppala, S.: The diabatic heat budget of the upper troposphere and lower/mid stratosphere in ECMWF reanalyses, Q. J. Roy. Meteor. Soc., 135, 21-37, doi:10.1002/qj.361, 2009b.

Fueglistaler, S., Liu, Y. S., Flannaghan, T. J., Haynes, P. H., Dee, D. P., Read, W. J., Remsberg, E. E., Thomason, L. W., Hurst, D. F., Lanzante, J. R., and Bernath, P. F.: The relation between atmospheric humidity and temperature trends for stratospheric water, J. Geophys. Res., 118, doi:10.1002/jgrd.50157, 2013.

Fujiwara, M. and Jackson, D.: SPARC Reanalysis Intercomparison Project (S-RIP) Planning Meeting, SPARC Newsletter, 41, 52$55,2013$.

Fujiwara, M., Polavarapu, S., and Jackson, D.: A proposal of the SPARC Reanalysis/Analysis Intercomparison Project, SPARC Newsletter, 38, 14-17, 2012a.

Fujiwara, M., Suzuki, J., Gettelman, A., Hegglin, M. I., Akiyoshi, H., and Shibata, K.: Wave activity in the tropical tropopause layer in seven reanalysis and four chemistry climate model data sets, J. Geophys. Res., 117, D12105, doi:10.1029/2011JD016808, 2012b.

Hoskins, B. J.: Towards a PV- $\theta$ view of the general circulation, Tellus, 43AB, 27-35, 1991.

Kalnay, E., Kanamitsu, M., Kistler, R., Collins, W., Deaven, D., Gandin, L., Iredell, M., Saha, S., White, G., Woollen, J., Zhu, Y., Leetmaa, A., Reynolds, R., Chelliah, M., Ebisuzaki, W., Higgins, W., Janowiak, J., Mo, K. C., Ropelewski, C., Wang, J., Jenne, R., and Joseph, D.: The NCEP/NCAR 40-Year Reanalysis Project, B. Am. Meteorol. Soc., 77, 437-471, 1996.

Lacis, A. A. and Hansen, J. E.: A parameterization for the absorption of solar radiation in the Earth's atmosphere, J. Atmos. Sci., 31, 118-133, 1974.

Ling, J. and Zhang, C.: Diabatic heating profiles in recent global reanalyses, J. Climate, 26, 3307-3325, doi:10.1175/JCLI-D-1200384.1, 2013.

Mcfarlane, S. A., Mather, J. H., and Ackerman, T. P.: Analysis of tropical radiative heating profiles: A comparison of models and observations, J. Geophys. Res., 112, D14218, doi:10.1029/2006JD008290, 2007.

Mlawer, E. J., Taubman, S. J., Brown, P. D., Iacono, M. J., and Clough, S. A.: Radiative transfer for inhomogeneous atmospheres: RRTM, a validated correlated-k model for the long wave, J. Geophys. Res., 102, 16663-16682, 1997.

Onogi, K., Tsutsui, J., Koide, H., Sakamoto, M., Kobayashi, S., Hatsushika, H., Matsumoto, T., Yamazaki, N., Kamahori, H., Takahashi, K., Kadokura, S., Wada, K., Kato, K., Oyama, R., Ose, T., Mannoji, N., and Taira, R.: The JRA-25 Reanalysis, J. Meteor. Soc. Jpn., 85, 369-432, doi:10.2151/jmsj.85.369, 2007.

Pawson, S. and Fiorino, M.: A comparison of reanalyses in the tropical stratosphere: Part 1: thermal structure and the annual cycle, Clim. Dynam., 14, 631-644, 1998.

Peixoto, J. P. and Oort, A. H.: Physics of Climate, American Institute of Physics, New York, NY, USA, 1992.

Plumb, R. A. and Eluszkiewicz, J.: The Brewer-Dobson circulation: Dynamics of the tropical upwelling, J. Atmos. Sci., 56, 868-890, 1999. 
Rienecker, M. M., Suarez, M. J., Gelaro, R., Todling, R., Bacmeister, J., Liu, E., Bosilovich, M. G., Schubert, S. D., Takacs, L., Kim, G.-K., Bloom, S., Chen, J., Collins, D., Conaty, A., da Silva, A., Gu, W., Joiner, J., Koster, R. D., Lucchesi, R., Molod, A., Owens, T., Pawson, S., Pegion, P., Redder, C. R., Reichle, R., Robertson, F. R., Ruddick, A. G., Sienkiewicz, M., and Woollen, J.: MERRA: NASA's Modern-Era Retrospective Analysis for Research and Applications, J. Climate, 24, 3624-3648, doi:10.1175/JCLI-D-11-00015.1, 2011.

Saha, S., Moorthi, S., Pan, H.-L., Wu, X., Wang, J., Nadiga, S., Tripp, P., Kistler, R., Woollen, J., Behringer, D., Liu, H., Stokes, D., Grumbine, R., Gayno, G., Wang, J., Hou, Y.-T., Chuang, H.Y., Juang, H.-M. H., Sela, J., Iredell, M., Treadon, R., Kleist, D., Van Delst, P., Keyser, D., Derber, J., Ek, M., Meng, J., Wei, H., Yang, R., Lord, S., Van Den Dool, H., Kumar, A., Wang, W., Long, C., Chelliah, M., Xue, Y., Huang, B., Schemm, J.-K., Ebisuzaki, W., Lin, R., Xie, P., Chen, M., Zhou, S., Higgins, W., Zou, C.-Z., Liu, Q., Chen, Y., Han, Y., Cucurull, L., Reynolds, R. W., Rutledge, G., and Goldberg, M.: The NCEP Climate Forecast System Reanalysis, B. Am. Meteorol. Soc., 91, 1015-1057, doi:10.1175/2010BAMS3001.1, 2010.

Schoeberl, M. R., Dessler, A. E., and Wang, T.: Simulation of stratospheric water vapor and trends using three reanalyses, Atmos. Chem. Phys., 12, 6475-6487, doi:10.5194/acp-12-6475-2012, 2012.
Schwarzkopf, M. D. and Fels, S.: The simplified exchange method revisited: an accurate, rapid method for computation of infrared cooling rates and fluxes, J. Geophys. Res., 96, 9075-9096, 1991.

Seidel, D. J., Free, M., and Wang, J. S.: Reexamining the warming in the tropical upper troposphere: Models versus radiosonde observations, Geophys. Res. Lett., 39, L22701, doi:10.1029/2012GL053850, 2012.

Sugi, M., Kuma, K., Tada, K., Tamiya, K., Hasegawa, N., Iwasaki, T., Yamada, S., and Kitade, T.: Description and performance of the JMA operational global spectral model (JMA GSM88), Geophys. Mag., 43, 105-130, 1990.

Thompson, A. M., Witte, J. C., McPeters, R. D., Oltmans, S. J., Schmidlin, F. J., Logan, J. A., Fujiwara, M., Kirchhoff, V. W. J. H., Posny, F., Coetzee, G. J. R., Hoegger, B., Kawakami, S., Ogawa, T., Johnson, B. J., Vömel, H., and Labow, G.: Southern Hemisphere Additional Ozonesondes (SHADOZ) 1998-2000 tropical ozone climatology 1. Comparison with Total Ozone Mapping Spectrometer (TOMS) and ground-based measurements, J. Geophys. Res. Atmos., 108, 8238, doi:10.1029/2001JD000967, 2003.

Yang, Q., Fu, Q., and $\mathrm{Hu}$, Y.: Radiative impacts of clouds in the tropical tropopause layer, J. Geophys. Res., 115, D00H12, doi:10.1029/2009JD012393, 2010. 